\title{
LIPONEURA MATRIS, \\ A NEW NET-WINGED MIDGE FROM THE SOUTH OF FRANCE [DIPTERA : BLEPHARICERIDAE]
}

by Peter ZWICK $^{1}$

Liponeura matris sp. n. (Diptera: Blephariceridae) from Département Aude, France, is described and compared to the closely related sympatric $L$. decipiens. and $L$. deceptiva.

\section{Liponeura maśris, un nouveau Blépharicéride du sud de la France [Diptera]}

L. matris n. sp., capturée dans le département de l'Aude, est décrite et comparée à deux espèces affines et sympatriques, $L$. decipiens et $L$. deceptiva.

Details of the male genitalia distinguish the close relatives of Liponeura decipiens Bezzi from their congeners. They form a homogenous group in which only males can be identified all the time. This applies also to the French species dealt with here. Most of the members of the group occur on lands surrounding or on islands in the western Mediterranean Sea and this is probably the area where the group developed. $L$. decipiens itself extends far to the north and east and reaches the western Carpathians and the northern end of the Dinari. mountains. L. vimmeri Mannheims probably belongs to this group but is somewhat aberrant; it is of Balkanian distribution, with a narrow extension along the Carpathians into central Europe as far west as the Harz Mts. in Germany.

Two members of the decipiens group, viz. $L$. decipiens and $L$. deceptiva Vaillant, were previously known from France and are known to coexist in places (Giudicelli and Lavandier 1975). Unexpectedly, a third undescribed species in this complex has now been found in the south of France, together with L. deceptiva.

\section{Liponeura matris sp. n.}

Holotype $\delta, 3$ s paratypes (all pharate specimens), France, Dpt. Aude, Montagne Noire $\mathrm{N}$. of Carcassonne, La Dure at Cuxac-Cabardes,

1. Limnologische Flußstation des Max-Planck-Instituts für Limnologie, Postfach 260, D-6407 Schlitz, Federal Republic of Germany. 
approx. $600 \mathrm{~m}, 18 . \mathrm{V} .1981$, P. Zwick ; in my collection in the Limnologische Flussstation Schlitz.

of (pharate specimen): wing almost $9 \mathrm{~mm}$ long. General structure typical of the genus, not distinctive. Flagellar segments elongate, basal ones 2, distal ones 2.5 times longer than wide, each widest a little basally from its middle and with a few setae near middle. Last segment 3 times longer than wide, constricted near middle, tip blunt, setose. Eyes normal, simple. Rostrum about as long as head high, mandibles and hypopharynx reduced, maxillary palpi and labium well developed, as usual. Thorax and legs normal, a basal swelling beset with strong spine-like setae present on last tarsal segment. Tarsal claws slender, 5-8 sharp secondary teeth on their basal two thirds. Abdomen normal.

Genitalia (Fig. 1-3) : dorsal plate and cerci simple, cerci are rounded setose lobes separated by a slightly concave V-shaped notch. Hypopygium short and very wide, its ventrodistal margin straight, not pointed. Forceps short, angularly notched on the outside opposite a very large posteriorly expanded inner process. The medially inclined base of the forceps is bare. The apical part is narrow and has a small, slightly expanded tip turned medially; it is setose on the outside. A few fine hairs are present on the dorsal side of the inner process. The soft ventral lobe of the forceps is regularly curved, ovoid, the narrow end is medial. Inner dististyle large, with paramedian furrow, outer sclerotized face forming a narrow apical lobe and a blunt process.

: not known.

Pupa : up to $6.5 \mathrm{~mm}$ long, not satisfactorily distinguishable from pupae of $L$. deceptiva and $L$. decipiens, the only consistent difference is the somewhat sparser and therefore seemingly coarser granulation of L. matris (Fig. 4, 5).

Larva: : not known.

Remarks : apart from marked differences of the forceps shown (Fig. 2-3, 6-9; note the distinctive tooth on the ventral lobe of $L$. deceptiva, which was not mentioned in the original description, Vaillant 1968), L. matris differs from its sympatric relatives, viz. $L$. decipiens and L. deceptiva, by a truncate (instead of pointed) ventrodistal margin of the hypopygium and the outer lobe of the inner dististyle which hides the huge inner process of the forceps. In dorsal view, the sclerotized apex of the forceps is fairly similar to those of $L$. edwardsi Bischoff (Corsica) and L. limomi Zwick (Sicily) but lateral views differ strongly, as do the shape of the inner process and the soft ventral lobe of the forceps, the form of the inner dististyle, and of the ventrodistal edge of the hypopygium.

The new species was found amidst numbers of $L$. deceptiva and if larvae of $L$. matris are contained in the sample, they cannot be distin. 
guished from those of $L$. deceptiva, nor from those of $L$. decipiens. A few immature pupae wich are probably L. matris are all males, indicating that the species was just beginning to pupate. The type iocality is a clear cool calmly flowing trout stream. The presence of Blepharicera fasciata (Westwood) suggests that it warms up considerably in summer. The pupae of L. deceptiva at this place were as large

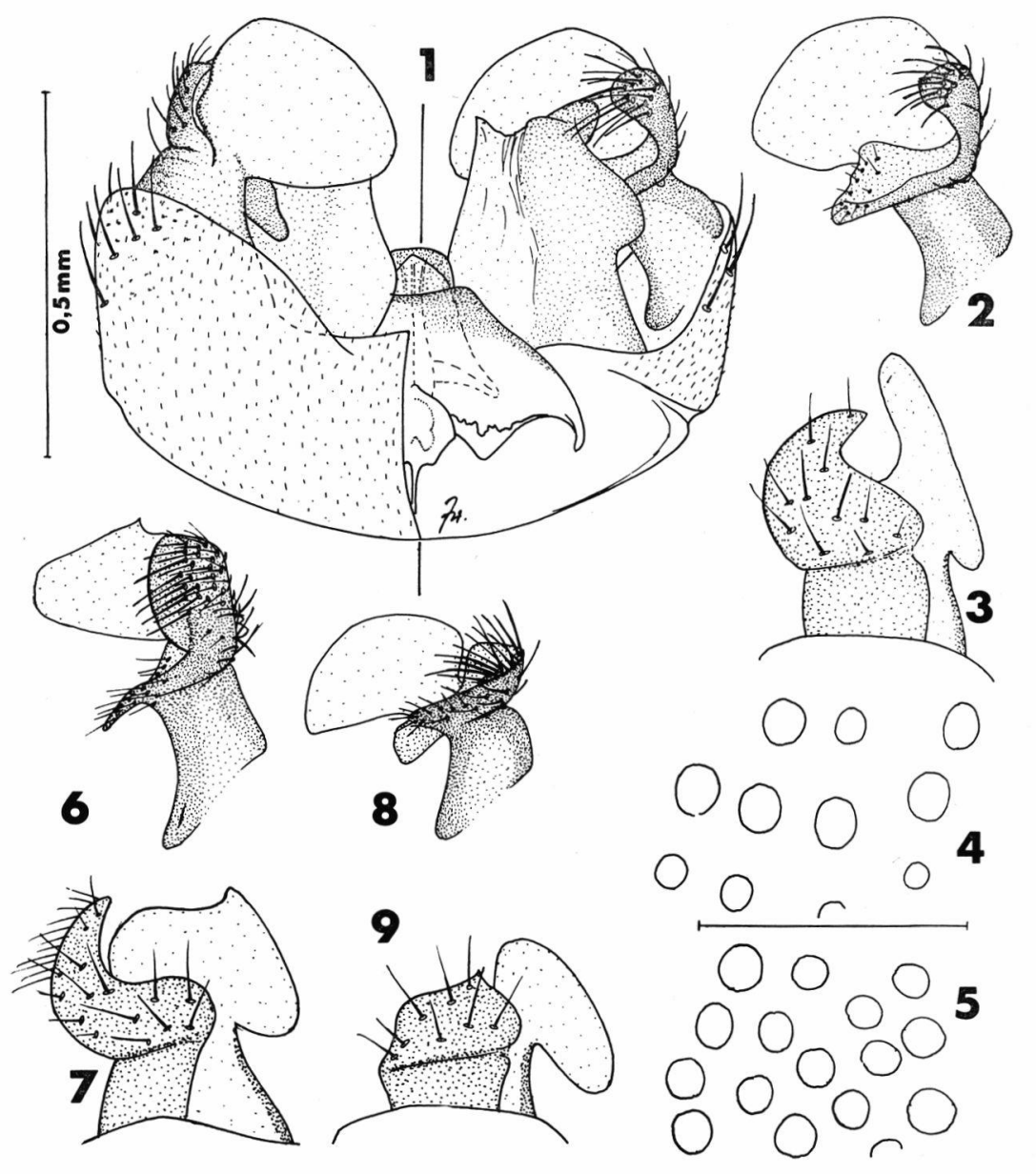

FIG. 1-4. - Liponeura matris sp. n. - 1: $\hat{\circ}$ hypopygium, dorsal plate and cerci removed, in ventral (left) and dorsal views (right) ; 2 : left forceps in dorsal view ; 3: the same, lateral view ; 4 : abdominal tergite 3 of pupa, granulation immediately to the outside of major muscle attachments, scale line is $0.1 \mathrm{~mm}$.

ïI. 5-7. - Liponeura deceptiva Vaillant. - 5: abdominal tergite 3 of pupa, granulation immediately to the outside of major muscle attachments, scale line is $0.1 \mathrm{~mm} ; 6$ : left forceps of $\hat{s}$, dorsal view ; $7:$ the same, lateral view.

FIG. 8-9. - Liponeura decipiens Bezzi. -8 : left forceps of 8 , dorsal view; 9 : the same, lateral view. 
or larger than those of L. matris, that is, distinctly larger than specimens I have seen from other places.

L. matris is gratefully dedicated to my mother for her untiring support of my entomological interests since my childhood.

\section{REFERENCES}

Giudicelli (J.) et LavandieR (P.). 1975. - Les Blépharocérides de la Vallée d'Aure (Hautes-Pyrénées, France): systématique et écologie (Dipt., Nematocera). Annls Limnol., 10 (1974) : 245-261.

Vaillant (F.). 1968. - Les Diptères Blepharoceridae de la France continentale. Trav. Lab. Hydrobiol., Grenoble, 59-60: 103-115.

Paru en mars 1982. 